\title{
Spatial analysis and risk mapping of Fasciola bepatica infection in dairy herds in Ireland
}

\author{
Nikolaos Selemetas ${ }^{1}$, Els Ducheyne 2 , Paul Phelan³, Padraig O’Kiely ${ }^{3}$, Guy Hendrickx², Theo \\ de $\mathrm{Waal}^{1}$ \\ ${ }^{1}$ UCD School of Veterinary Medicine, University College Dublin, Dublin, Ireland; ${ }^{2}$ Avia-GIS, Zoersel, Belgium; \\ ${ }^{3}$ Animal and Grassland Research and Innovation Centre, Teagasc, Grange, Dunsany Co, Meath, Ireland
}

\begin{abstract}
Fasciolosis is generally a subclinical infection of dairy cows and can cause marked economic losses. This study investigated the prevalence and spatial distribution of fasciolosis in dairy cow herds in Ireland using an in-house antibodydetection enzyme-linked immunosorbent assay applied to bulk tank milk (BTM) samples collected during the autumn of 2012. A total of 5,116 BTM samples were collected from 4,602 different herds, with 514 farmers submitting BTM samples in two consecutive months. Analysis of the BTM samples showed that $82 \%(\mathrm{n}=3,764)$ of the dairy herds had been exposed to Fasciola hepatica. A total of 108 variables, including averaged climatic data for the period 1981-2010 and contemporary meteorological data for the year 2012, such as soil, subsoil, land cover and habitat maps, were investigated for a possible role as predictor of fasciolosis. Using mainly climatic variables as the major predictors, a model of the predicted risk of fasciolosis was created by Random Forest modelling that had $95 \%$ sensitivity and $100 \%$ specificity. The most important predictors in descending order of importance were: average of annual total number of rain-days for the period 1981-2010, total rainfall during September, winter and autumn of 2012, average of annual total number of wet-days for the period 19812010 and annual mean temperature of 2012. The findings of this study confirm the high prevalence of fasciolosis in Irish dairy herds and suggest that specific weather and environmental risk factors support a robust and precise distribution model.
\end{abstract}

Keywords: fasciolosis, Fasciola hepatica, spatial analysis, Random Forest, modelling, Ireland.

\section{Introduction}

Fasciolosis caused by Fasciola hepatica, although a subclinical parasitic disease, has a negative influence on cattle productivity and can cause major economic losses in cattle farming (Kaplan, 2001). The single most important cause of economic loss due to fasciolosis in dairy cattle is reduced milk production (Schweizer et al., 2005, Charlier et al., 2012). Fasciolosis depends greatly on environmental characteristics and climatic conditions, therefore climate change may noticeably alter the future development of the disease (Mas-Coma et al., 2009). In particular, apart from presence of suitable livestock hosts, sufficient moisture and an ambient temperature above $+10{ }^{\circ} \mathrm{C}$ are required for the development of the freeliving and intra-molluscan stages of F. hepatica as well as the development of the intermediate snail hosts (Torgerson and Claxton, 1999).

Corresponding author:

Theo de Waal

School of Veterinary Medicine, University College Dublin UCD Veterinary Sciences Centre

Belfield, Dublin 4, Ireland

Tel. +353 1716-6178; Fax +353 1716-6185

E-mail: theo.dewaal@ucd.ie
There is limited knowledge on the prevalence of fasciolosis in Irish cattle herds. Murphy et al. (2006) found that $65 \%$ of culled cattle from beef and dairy farms throughout Ireland had infected livers, while Bloemhoff et al. (2012) demonstrated that $75 \%$ of the dairy herds in November 2009 had been exposed to F. hepatica. In Ireland, the Ollerenshaw index is presently used to predict the incidence of fasciolosis based on monthly measurements of rainfall, number of rain-days and evapotranspiration (de Waal et al., 2007). This regional, forecast system is intended to regulate treatment regimens and, although working relatively well, it still lacks the ability to predict incidence levels accurately. It is also used on a much smaller scale than the regional one in order to maximise the return on the producer's investment in disease control (Smith, 2011). Finally, there is a paucity of nationalscale, long-term studies with detailed and consistent data on the spatial distribution of fasciolosis in Ireland.

Spatial risk models for fasciolosis using geographical information systems (GIS) have been applied in Africa (Malone et al., 1998; Yilma and Malone, 1998), South America (Fuentes and Malone, 1999; Fuentes et al., 2005; Fuentes, 2006; Dutra et al., 2010; Martins et al., 2012; Valencia-López et al., 2012), USA (Malone and Zukowski, 1992; Zukowski et al., 1993), Australia 
(Durr et al., 2005), Cambodia (Tum et al., 2004, 2007) and Europe (Rapsch et al., 2008; McCann et al., 2010a; Bennema et al., 2011; Charlier et al., 2011; Kuerpick et al., 2013). The incorporation of climatic, environmental and pasture variables into these detailed, spatial models can explain the observed seasonal pattern of fasciolosis at the regional level and allow predictions of the disease risk in order to help farmers make informed decisions on its control (McCann et al., 2010a).

In this study, we present a new approach to predict the spatial distribution of fasciolosis that is based on Random Forest (RF) modelling using numerous climatic and environmental datasets. The objectives of this study were: (i) to evaluate the prevalence of fasciolosis in Irish dairy cow herds; (ii) to identify its main potential climatic and environmental risk factors; and (iii) to develop a prediction model for the occurrence of fasciolosis in dairy herds in Ireland allowing the construction of a risk map of the probability of exposure to the disease.

\section{Materials and methods}

\section{Study area}

The study was conducted in Ireland (surface area $=$ $69,825 \mathrm{~km}^{2}$ ) between September and November 2012. Ireland's climate is mild, without temperature extremes due to the moderating effect of the Atlantic Ocean (Walsh, 2012), which also results in higher annual mean temperature values in the coastal regions and higher total rainfall in the western half of the country and on the highlands (Fig. 1).

\section{ANNUAL MEAN TEMPERATURE}

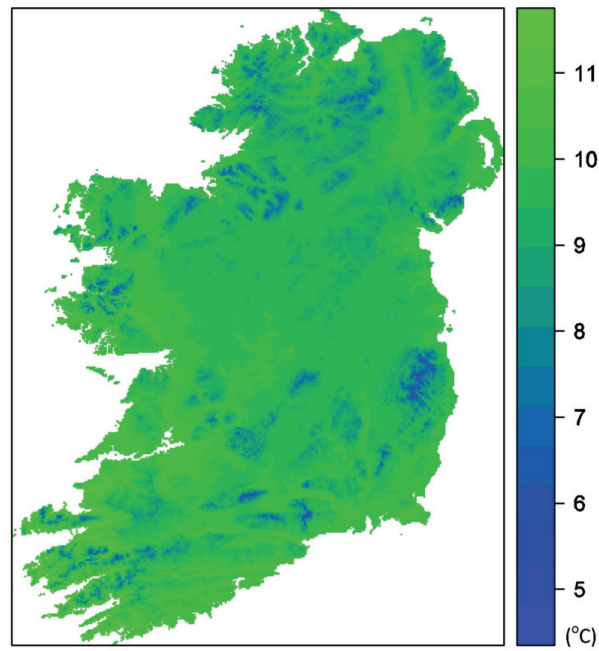

\section{Sample collection}

A total number of 5,116 bulk tank milk (BTM) samples were gathered between September and November 2012 from 514 farmers in 18 Irish counties representing 4,602 dairy herds. The greater proportion of the samples $(n=5,038)$ were collected by an Irish private cattle breeding services company, providing samples from nearly all dairy farmers in their database but not selected randomly. The remaining samples $(n=364)$ were collected either from dairy farmers that were members of discussion group-meetings supervised by the Agriculture and Food Development Authority of Ireland (Teagasc) agricultural advisors in the five counties of Cavan, Cork, Donegal, Offaly and Westmeath, including a small creamery in Donegal County. The postal address of each dairy farm providing a BTM sample was recorded and used as information regarding the geographical origin of the sample in question. When two BTM samples were submitted from the same herd, the sample with the higher F. hepatica antibodies level was used. BTM samples that could not be attributed to a postal address $(n=286)$ were excluded from further analysis.

Broad Spectrum Microtabs II, containing a combination of Bronopol and Natamycin (Advanced Instruments Inc, MA, USA), were used for the preservation of samples. All BTM samples were sent to the Veterinary Parasitology Laboratory of University College Dublin. After arrival at the laboratory, the BTM samples coming from the private company due to their large quantity were left to stand for at least 4 days at $+4{ }^{\circ} \mathrm{C}$ to allow the separation and removal of

\section{ANNUAL RAINFALL}

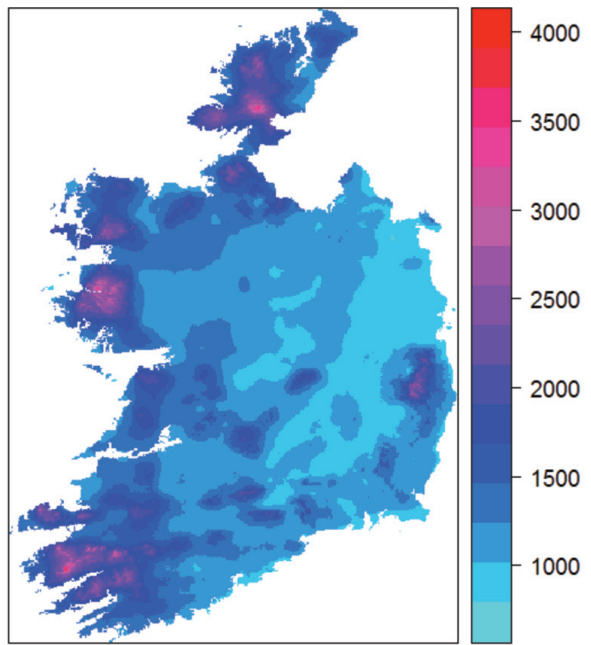

Fig. 1. Gridded maps of Ireland showing the distributions of annual mean temperatures and rainfall in 2012. 
the superficial fat layer before being tested. The remaining samples, after being stored at $+4{ }^{\circ} \mathrm{C}$ for eight hours, were centrifuged at $850 \mathrm{~g}$ for 10 minutes and the non-lipid fractions were divided into $2-\mathrm{ml}$ aliquots and stored at $-20^{\circ} \mathrm{C}$ until testing.

\section{Antibody testing}

The levels of F. hepatica antibodies in BTM samples were determined by an in-house antibody-detection ELISA as described previously (Selemetas et al., 2014). All BTM samples were left for 1-2 hours at room temperature before the start of testing. One negative and two positive controls were used as reference standards for calculation of the F. hepatica antibody levels, which were determined by measuring the optical density (OD) at the $450 \mathrm{~nm}$ wavelength in an ELISA micro-plate reader (Expert 96, Asys Hitech, Eugendorf, Austria). The mean OD value of all positive controls was used as an extra, internal control. The antibody levels of each BTM sample was expressed as per cent positivity (PP) according to the following formula:

$$
\mathrm{PP} \text { value }=\frac{O D \text { of test sample }}{\text { Mean OD of positive controls }} \times 100
$$

A mixture of two Gaussian distributions was fitted to the PP values of the BTM samples to determine the optimal cut-off value of the ELISA test. In the case of herds from which consecutive BTM samples were available, the higher PP value was used. The mixture model of the two components (positive and negative herds) was fitted using the Mixtools package in R (R Core Team, 2013) and the algorithm of expectation-maximization (EM) of the normal mixEM function (Benaglia et al., 2009). The optimal cut-off value of the whole population of the PP values of BTM samples in this study was 12 . Therefore, herds with a PP higher than 12 were deemed positive, whereas those with PPs $\leq 12$ were regarded as negative. On the basis of the frequency distributions shown in Fig. 2 and the large number of BTM samples ( $>5000)$, the $12 \mathrm{PP}$ threshold value is assumed to be very close to the optimal cut-off value of the ELISA results.

\section{Variables investigated}

This study used 108 climatic and environmental variables (Table 1) as possible predictors of the exposure to F. hepatica, including the following ones.

\section{Climatic data layers}

Climatic data based on the $1 \times 1 \mathrm{~km}$ resolution grid for Ireland were obtained from the archive of Irish weather observations provided by the Irish National Meteorological Service (Met Éireann) for the period 1981-2010 and the year of 2012 with the coordinates on the Irish Grid Reference System (TM75/Irish Grid). Datasets for the following weather parameters of the period 1981-2010 were used: averages of annual, seasonal and monthly mean, maximum and minimum temperatures $\left({ }^{\circ} \mathrm{C}\right)$, averages of annual, seasonal and monthly total rainfall $(\mathrm{mm})$ and total number of raindays (daily rainfall $\geq 0.2 \mathrm{~mm}$ ) and wet-days (daily rainfall $\geq 1 \mathrm{~mm}$ ). For the year 2012, the averages of annual, seasonal and monthly mean temperatures $\left({ }^{\circ} \mathrm{C}\right)$ and averages of annual, seasonal and monthly total rainfall $(\mathrm{mm})$ were used. The seasonal variables refer to the following 3-month periods: winter (December to February), spring (March to May), summer (June to August) and autumn (September to November). All these climatic data layers were converted from ASCII to raster format using the $\mathrm{R}$ 3.0.3 statistical language (R Core Team, 2013).

\section{Soil and environmental variables}

Data describing land cover information at a resolution of $20 \times 20 \mathrm{~m}$ was derived from the CORINE Land Cover (CLC2006) dataset for Ireland for the year 2006 (EEA, 2007), containing 33 classes including pasture, peat bogs, non-irrigated arable land, agricultural land, complex cultivation, forests and grassland. Data on different soil types (deep and shallow, welldrained, mineral, deep and shallow, poorly drained, mineral, peat alluvium) and subsoil type that can consist of till, sand and gravel alluvium, peat, marsh and glacio-lacustrine deposits were obtained from the

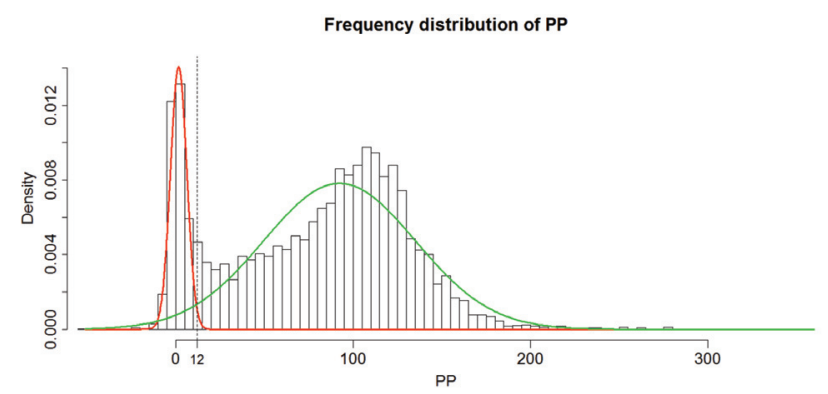

Fig. 2. Histogram of the frequency distribution of the ELISA per cent positivity (PP) values for the bulk tank milk (BTM) samples and the fitted Gaussian distributions of the two subgroups (positive and negative herds). 
Table 1. Properties, data sources and resolution of the climatic and environmental variables.

\begin{tabular}{|c|c|c|c|}
\hline Variable $^{1}$ & Period & Source & Spatial resolution \\
\hline Annual mean temperature & 2012 & Met Éireann & $1 \times 1 \mathrm{~km}$ \\
\hline Mean January-December 2012 temperature & January-December 2012 & Met Éireann & $1 \mathrm{x} 1 \mathrm{~km}$ \\
\hline Mean winter temperature & December 2011-February 2012 & Met Éireann & $1 \mathrm{x} 1 \mathrm{~km}$ \\
\hline Mean spring temperature & March-May 2012 & Met Éireann & $1 \times 1 \mathrm{~km}$ \\
\hline Mean summer temperature & June-August 2012 & Met Éireann & $1 \times 1 \mathrm{~km}$ \\
\hline Mean autumn temperature & September-November 2012 & Met Éireann & $1 \times 1 \mathrm{~km}$ \\
\hline Average annual mean temperature & 1981-2010 & Met Éireann & $1 \times 1 \mathrm{~km}$ \\
\hline Average January-December temperature & $1981-2010$ & Met Éireann & $1 \times 1 \mathrm{~km}$ \\
\hline Average winter temperature & December-February 1981-2010 & Met Éireann & $1 \times 1 \mathrm{~km}$ \\
\hline Average spring temperature & March-May 1981-2010 & Met Éireann & $1 \times 1 \mathrm{~km}$ \\
\hline Average summer temperature & June-August 1981-2010 & Met Éireann & $1 \times 1 \mathrm{~km}$ \\
\hline Mean autumn temperature & September-November 1981-2010 & Met Éireann & $1 \times 1 \mathrm{~km}$ \\
\hline Average maximum temperature & $1981-2010$ & Met Éireann & $1 \times 1 \mathrm{~km}$ \\
\hline Average January-December max. temperature & January-December 1981-2010 & Met Éireann & $1 \times 1 \mathrm{~km}$ \\
\hline Average winter max. temperature & December-February 1981-2010 & Met Éireann & $1 \times 1 \mathrm{~km}$ \\
\hline Average spring max. temperature & March-May 1981-2010 & Met Éireann & $1 \times 1 \mathrm{~km}$ \\
\hline Average summer max. temperature & June-August 1981-2010 & Met Éireann & $1 \times 1 \mathrm{~km}$ \\
\hline Average autumn max. temperature & September-November 1981-2010 & Met Éireann & $1 \times 1 \mathrm{~km}$ \\
\hline Average min. temperature & $1981-2010$ & Met Éireann & $1 \times 1 \mathrm{~km}$ \\
\hline Average January-December min. temperature & January-December1981-2010 & Met Éireann & $1 \times 1 \mathrm{~km}$ \\
\hline Average winter min. temperature & December-February 1981-2010 & Met Éireann & $1 \times 1 \mathrm{~km}$ \\
\hline Average spring min. temperature & March-May 1981-2010 & Met Éireann & $1 \times 1 \mathrm{~km}$ \\
\hline Average summer min. temperature & June-August 1981-2010 & Met Éireann & $1 \times 1 \mathrm{~km}$ \\
\hline Average autumn min. temperature & September-November 1981-2010 & Met Éireann & $1 \times 1 \mathrm{~km}$ \\
\hline Annual mean rainfall & 2012 & Met Éireann & $1 \times 1 \mathrm{~km}$ \\
\hline Mean January-December 2012 rainfall & January-December 2012 & Met Éireann & $1 \times 1 \mathrm{~km}$ \\
\hline Mean winter rainfall & December 2011-February 2012 & Met Éireann & $1 \times 1 \mathrm{~km}$ \\
\hline Mean spring rainfall & March-May 2012 & Met Éireann & $1 \times 1 \mathrm{~km}$ \\
\hline Mean summer rainfall & June-August 2012 & Met Éireann & $1 \times 1 \mathrm{~km}$ \\
\hline Mean autumn rainfall & September-November 2012 & Met Éireann & $1 \times 1 \mathrm{~km}$ \\
\hline Average annual mean rainfall & $1981-2010$ & Met Éireann & $1 \times 1 \mathrm{~km}$ \\
\hline Average January-December rainfall & January-December 1981-2010 & Met Éireann & $1 \times 1 \mathrm{~km}$ \\
\hline Average winter rainfall & December-February 1981-2010 & Met Éireann & $1 \times 1 \mathrm{~km}$ \\
\hline Average spring rainfall & March-May 1981-2010 & Met Éireann & $1 \times 1 \mathrm{~km}$ \\
\hline Average summer rainfall & June-August 1981-2010 & Met Éireann & $1 \times 1 \mathrm{~km}$ \\
\hline Average autumn rainfall & Sept-November 1981-2010 & Met Éireann & $1 \times 1 \mathrm{~km}$ \\
\hline Average of annual total rain-days & $1981-2010$ & Met Éireann & $1 \times 1 \mathrm{~km}$ \\
\hline Average of annual total wet-days & $1981-2010$ & Met Éireann & $1 \times 1 \mathrm{~km}$ \\
\hline Corine Land Cover 2006 & 2006 & $\mathrm{EEA}^{2}, \mathrm{EPA}^{3}$ & $20 \times 20 \mathrm{~m}$ \\
\hline Soil GIS data & 2006 & Teagasc ${ }^{4}, \mathrm{EPA}^{3}, \mathrm{FS}^{5} \mathrm{GSI}^{6}$ & $10 \times 10 \mathrm{~km}$ \\
\hline Subsoil GIS data & 2006 & Teagasc ${ }^{4}, \mathrm{EPA}^{3}, \mathrm{FS}^{5} \mathrm{GSI}^{6}$ & $10 \times 10 \mathrm{~km}$ \\
\hline Habitat Indicator Map & $1995-2008$ & Teagasc $^{4}$ & $25 \times 25 \mathrm{~m}$ \\
\hline
\end{tabular}

${ }^{1}$ Temperatures in ${ }^{\circ} \mathrm{C}$; rain in mm; ${ }^{2}$ European Environment Agency; ${ }^{3}$ Environmental Protection Agency, Ireland; ${ }^{4}$ Irish Agriculture and Food Development Authority; ${ }^{5}$ Forest Service; ${ }^{6}$ Geological Survey of Ireland. 
Environmental Protection Agency (EPA), Ireland and Teagasc's "Indicative Soils and Subsoils Maps" at the $10 \times 10 \mathrm{~km}$ resolution (Daly and Fealy, 2007). Data describing different habitat types (wet and dry grassland, water, rock, forest, fen, bog, wetland, salt marsh) were obtained from the Teagasc "National Habitat Indicator Map" at the $25 \times 25 \mathrm{~m}$ resolution (Fossitt, 2000). Using ArcGIS, v. 10.1 (ESRI, Redlands, CA, USA), all data layer shapefiles were converted into rasters and then all the values of each raster within each Irish electoral division (the smallest administrative unit in Ireland) were summarised (using the Zonal Statistics tool) and exported to an Excel table as either the mean value for all climatic (numerical) variables or the majority value for the other environmental (categorical) variables.

\section{GIS mapping and georeferencing}

The GIS used in the present study for the construction of spatial maps was ArcGIS, version 10.1. Based on the townland (the smallest legally defined administrative area in Ireland) location, each dairy herd was georeferenced by assigning its location to a point of the Google satellite map. If only a single farm existed on the satellite map of the townland, then a point was aligned on that farm and its coordinates were to that point. In the case of more than one farm on the satellite map of the townland, the points were aligned approximately on the centre of the townland.

\section{Modelling}

\section{The Random Forest (RF) approach}

The risk model of exposure to F hepatica was generated using the RF methodology (Breiman, 2001). This method has mainly been used in bioinformatics and ecology and is popular due to its simplicity and ability to handle complex data of different statistical distributions together, while being computationally lighter than other machine-learning techniques (Cutler et al., 2007; Rodriguez-Galiano et al., 2014). This approach represents a powerful data-mining tool that can model complex interactions between different predictor variables and determine variable importance with great classification accuracy, which outperforms traditional modelling methods such as logistic regression (Cutler et al., 2007). RF is a mixture of tree-based predictors that are randomly constructed by bootstrapping from the complete dataset with replacement, so that it retains the same distribution as the full dataset (Breiman, 2001). Around one third of the data were randomly excluded from bootstrapping and the creation of the forest, comprising the "out-of-bag" (OOB) dataset, which was used as an independent cross-validation dataset to estimate the error rate of misclassified data from the bootstrap samples that comprise the forest.

\section{Construction of risk map of $\mathrm{F}$. hepatica exposure}

The dairy herds were classified into positive and negative classes, based on their status of exposure to F. hepatica as determined by the mixture bimodal model. The finest spatial map unit that was used in the current study was that of an electoral division. If an electoral division contained at least one positive herd, then it was regarded as positive. The raster describing the F. hepatica prevalence at the electoral division level was converted, together with all the possible predictor variables rasters, to database-formatted (dbf) files containing summary statistics for every data layer based on the code number of the electoral divisions. A balanced set of positive and negative electoral divisions was randomly selected each time to increase the accuracy of the probability model. Firstly, the probability of exposure to F. hepatica was measured using the RF methodology. Then, the correlation between the probability of exposure and several probable predictor variables were established and finally the probability of exposure to F. hepatica was used in combination with the most important risk factors to predict the risk of exposure. The RF modelling was performed in $\mathrm{R}$ 3.0.2 statistical language environment using the Rpackage "Random Forest", version 4.6-7.

\section{Importance of risk predictors in the RF model}

The importance of various predictors is determined by the decline in model performance through the average decrease of the Gini index that measures the contribution of each variable to homogeneity of nodes and leaves of the final RF (Breiman, 2001). Every time a specific variable is used to split a node, the Gini index is calculated for the child nodes after being compared to that of the original node and at the end of the calculations the Gini index changes for every variable are summed and normalised. Variables that generate nodes with greater purity have a higher reduction of the Gini index. The accuracy of the risk model of exposure to F. hepatica was evaluated using sensitivity, specificity and the percentage of correctly classified instances (PCC). 


\section{Statistical analysis}

The data were analysed and descriptive statistics including group means, were calculated using SPSS Statistics version 20.0 (IBM Corp, NY, USA). The chisquare test was used to determine significant differences between the exposed and non-exposed electoral divisions with the soil types variables. The significance was set at $\mathrm{P}<0.05$.

\section{Results}

\section{Prevalence}

The distribution of herds that submitted BTM samples in this study is depicted in Fig. 3. The analysis of the BTM samples shows that $82 \%(n=3,764)$ were exposed to F. hepatica. The monthly prevalence of fasciolosis was $66 \%$ in September, $85 \%$ in October and $87 \%$ in November. Table 2 summarises the distribution of BTM samples per county and the prevalence of fasciolosis for each county.

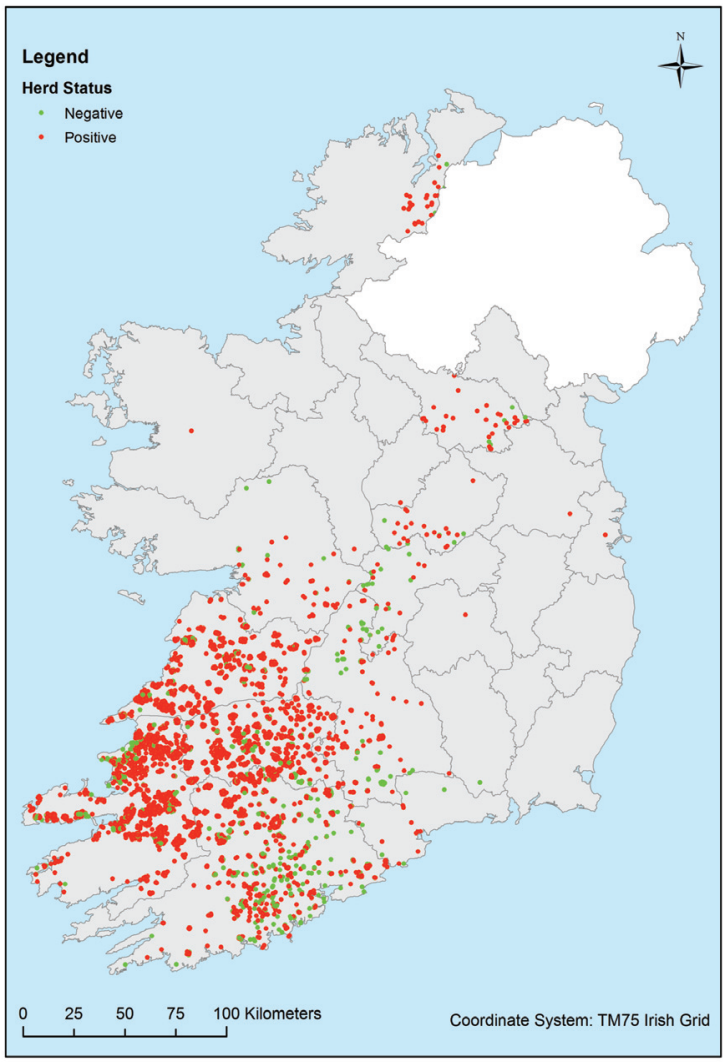

Fig. 3. County map of Ireland showing location and results (F. hepatica positive/negative) of all dairy herds.
Table 2. Distribution of bulk tank milk (BTM) samples tested for fasciolosis per county and the prevalence of fasciolosis for each county.

\begin{tabular}{lrrrc}
\hline County & $\begin{array}{c}\text { Herds } \\
(\mathrm{n})\end{array}$ & $\begin{array}{r}\text { Negative } \\
(\mathrm{PP}<12)\end{array}$ & $\begin{array}{r}\text { Positive } \\
(\mathrm{PP} \geq 12)\end{array}$ & $\begin{array}{c}\text { Prevalence } \\
(\%)\end{array}$ \\
\hline Clare & 493 & 38 & 455 & 92 \\
Donegal & 28 & 3 & 25 & 89 \\
Kerry & 1,420 & 178 & 1,242 & 87 \\
Cavan & 37 & 5 & 32 & 86 \\
Limerick & 1,144 & 172 & 972 & 85 \\
Galway & 77 & 15 & 62 & 81 \\
Westmeath & 25 & 6 & 19 & 76 \\
Cork & 1,152 & 342 & 810 & 70 \\
Tipperary & 173 & 55 & 118 & 68 \\
Waterford & 15 & 5 & 10 & 67 \\
Offaly & 31 & 18 & 13 & 42 \\
Dublin & 1 & 0 & 1 & - \\
Kilkenny & 1 & 1 & 0 & - \\
Laois & 1 & 0 & 1 & - \\
Longford & 1 & 0 & 1 & - \\
Mayo & 1 & 0 & 1 & - \\
Meath & 1 & 0 & 1 & - \\
Roscommon & 1 & 0 & 1 & - \\
Total & 4,602 & 838 & 3,764 & 82 \\
\hline In cane & & 15 & & - \\
\hline
\end{tabular}

In the case of herds with double BTM samples, the higher percent positivity (PP) value was used.

\section{Evaluation of spatial distribution}

The observed distribution of fasciolosis throughout Ireland is illustrated in Fig. 4. A higher proportion of F. hepatica-infected areas was found in the western part of the country. Fig. 5 illustrates the 20 most important variables driving the RF predictive model for fasciolosis. The geographical distribution of exposure to F. hepatica is most strongly associated with rainfall and temperature. The most important risk factors in descending order of importance were the following: (i) the average of annual total number of rain-days for the period 1981-2010; (ii) the total amount of rainfall during September, winter and autumn of 2012; (iii) the average of annual total number of wet-days; (iv) the total amount of rainfall during January of 2012; (v) the annual mean temperature of 2012; and the total amount of rainfall during March of 2012 (Fig. 5). In addition, the soil dataset was regarded as a predictor of low importance compared to the other risk factors, and all the other environmental variables (land cover, subsoil, habitat maps) were not considered as potential risk 


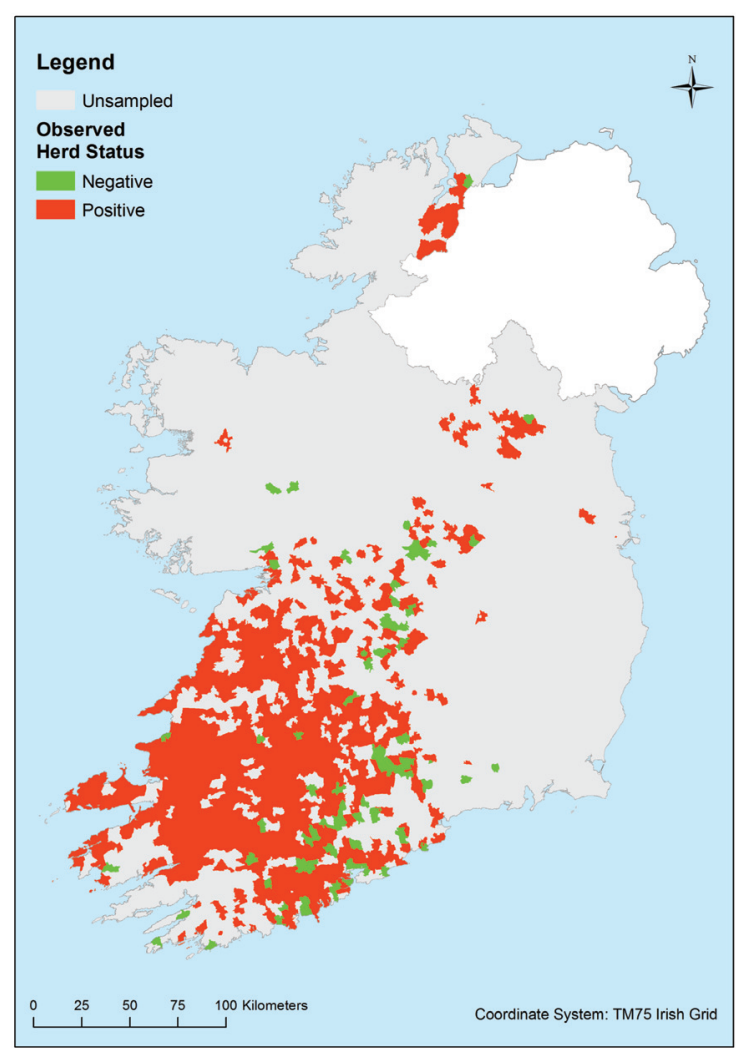

Fig. 4. Map of Ireland illustrating the observed distribution of exposed and non-exposed electoral divisions to F. hepatica based on the results of the sampled dairy herds. factors for fasciolosis (Fig. 5). The soil types that were mostly associated with significant differences between positive and negative regions for fasciolosis, as seen in Table 3, were deep, well-drained soils ( $\mathrm{P}<0.001)$, deep, poorly drained soils $(\mathrm{P}<0.001)$ and alluvium soils $(\mathrm{P}<0.05)$ consisting of fine particles of clay, silt and larger particles (sand and gravel). Fig. 6 depicts the probability of exposure to F. hepatica for 2012 based on the RF probability model. Overall, the accuracy of the predictive model was $97.5 \%$ PCC, 95\% sensitivity and $100 \%$ specificity. Fig. 7 illustrates the comparison of the observed and predicted distribution of fasciolosis by presenting the true negative, true positive and false negative predicted electoral divisions being exposed to F. hepatica; no false positives were found.

\section{Discussion}

The present study is the first national-scale approach that attempts to determine the prevalence of fasciolosis in Irish dairy cow herds, as nearly one third of the dairy herds in Ireland were tested for F. hepatica antibodies. The analysis of BTM samples showed that $82 \%$ of the dairy herds had been exposed to F. hepat$i c a$, which provides evidence for the high prevalence of fasciolosis in Irish dairy herds.

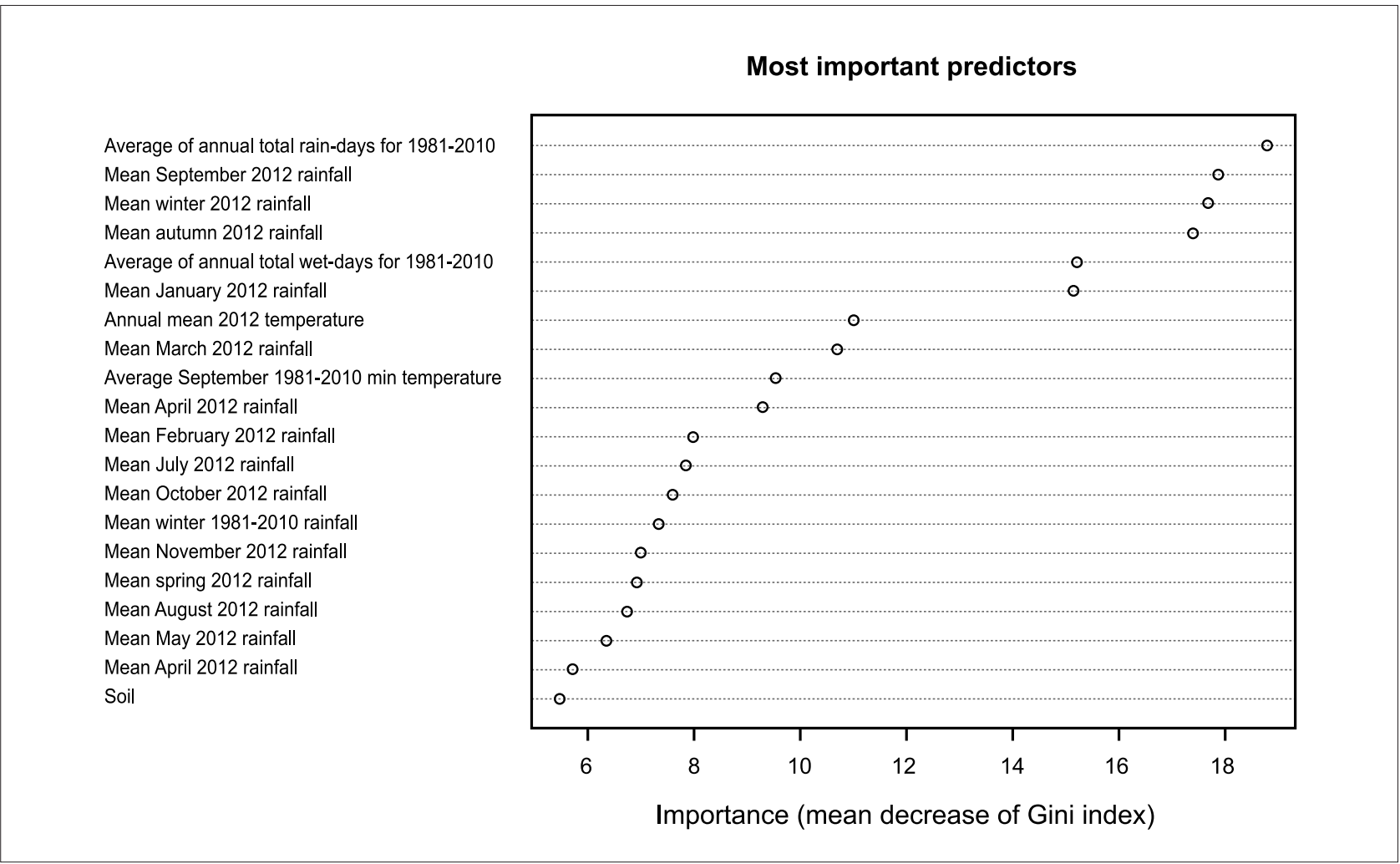

Fig. 5. The 20 most important predictors indicated by the variable importance (mean decrease of Gini index) for the probability of exposure to $F$. hepatica. 
Table 3. Results of the Pearson chi-square statistic test $\left(\chi^{2}\right)$ for significant differences between the exposed and non-exposed electoral divisions to Fasciola hepatica with respect to soil type.

\begin{tabular}{|c|c|c|c|c|c|}
\hline Soil type & $\begin{array}{l}\text { Negative count } \\
\text { (expected) }\end{array}$ & $\begin{array}{l}\text { Positive count } \\
\text { (expected) }\end{array}$ & $\begin{array}{l}\text { Total count } \\
\qquad(\%)\end{array}$ & $\chi^{2}$ & $\mathrm{P}$ \\
\hline Deep, well-drained & $61(37.9)$ & $331(354.1)$ & $392(48.9)$ & 15.59 & $<0.001$ \\
\hline Shallow, well-drained & $1(3.4)$ & $34(31.6)$ & $35(4.4)$ & 1.88 & 0.171 \\
\hline Deep, poorly drained & $5(21.4)$ & $217(200.6)$ & $222(27.7)$ & 13.91 & $<0.001$ \\
\hline Poorly drained, peaty top & $3(4.3)$ & $41(39.7)$ & $44(5.5)$ & 0.44 & 0.509 \\
\hline Alluvial & $0(3.7)$ & $38(34.3)$ & $38(4.7)$ & 4.07 & 0.043 \\
\hline Peats & $5(6.9)$ & $66(64.1)$ & $71(8.8)$ & 0.58 & 0.447 \\
\hline
\end{tabular}

These findings are very similar to the $65 \%$ prevalence in culled cows in Ireland during autumn and summer as reported by Murphy et al. (2006) and to the $75 \%$ prevalence in November among Irish dairy herds (Bloemhoff et al., 2012). The findings are also in accordance with the prevalence observed in Wales $(84 \%)$ and England $(72 \%)$ in the winter of 2006-2007 (McCann et al., 2010a). However, the prevalence of fasciolosis in the present study is higher than that reported for Sweden (7\%) by Höglund et al. (2010), for Belgium (31-40\%) by Bennema et al. $(2009,2011)$ and Charlier et al. (2013) and for Germany (24-57\%) by Kuerpick et al. $(2012,2013)$. The high prevalence of fasciolosis in Ireland seen in this study in compari-

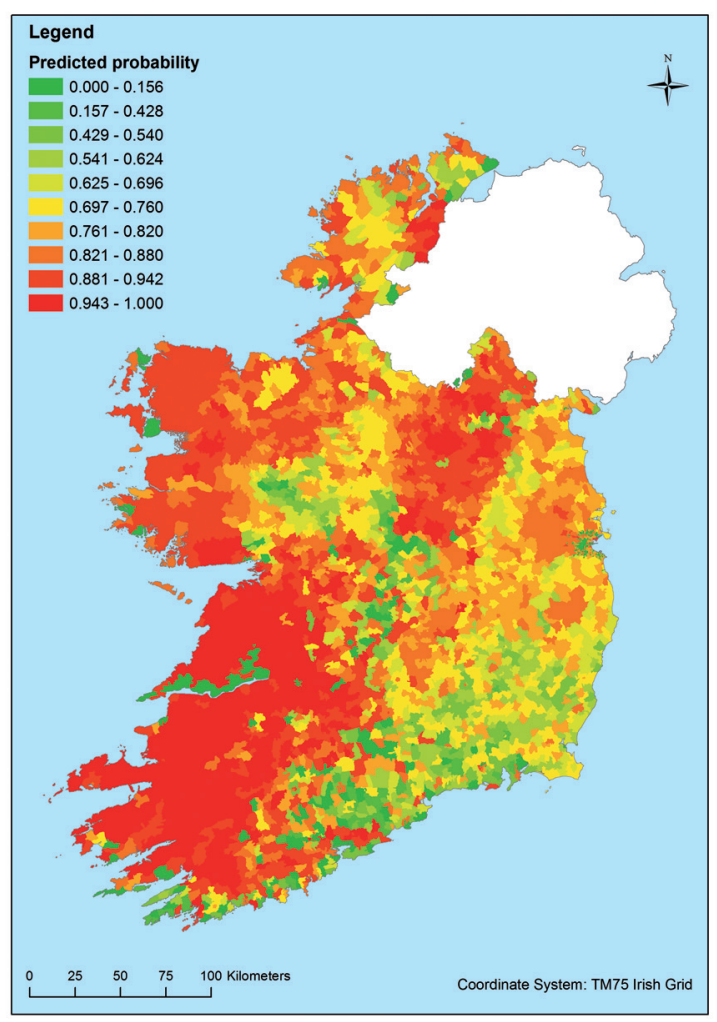

Fig. 6. Choropleth map of Ireland displaying the predicted probability of exposure of electoral divisions to $F$. hepatica. son with other European countries may be related either to different testing protocols and geographical coverage (Kuerpick et al., 2013) or to differences in precipitation, temperature, farm management and grazing conditions (McCann et al., 2010a; Bennema et al., 2011). Indeed, the basic difference and main competitive advantage of dairy farming in Ireland compared to other EU countries is the temperate climate that favours a low-cost grass-based production system (Creighton et al., 2011; Läpple et al., 2012). The major features of Irish dairy farming management are: (i) spring-calving; (ii) a pasture-based system where the main feed source is grass; and (iii) a grazing season from early spring to late autumn that permits dairy

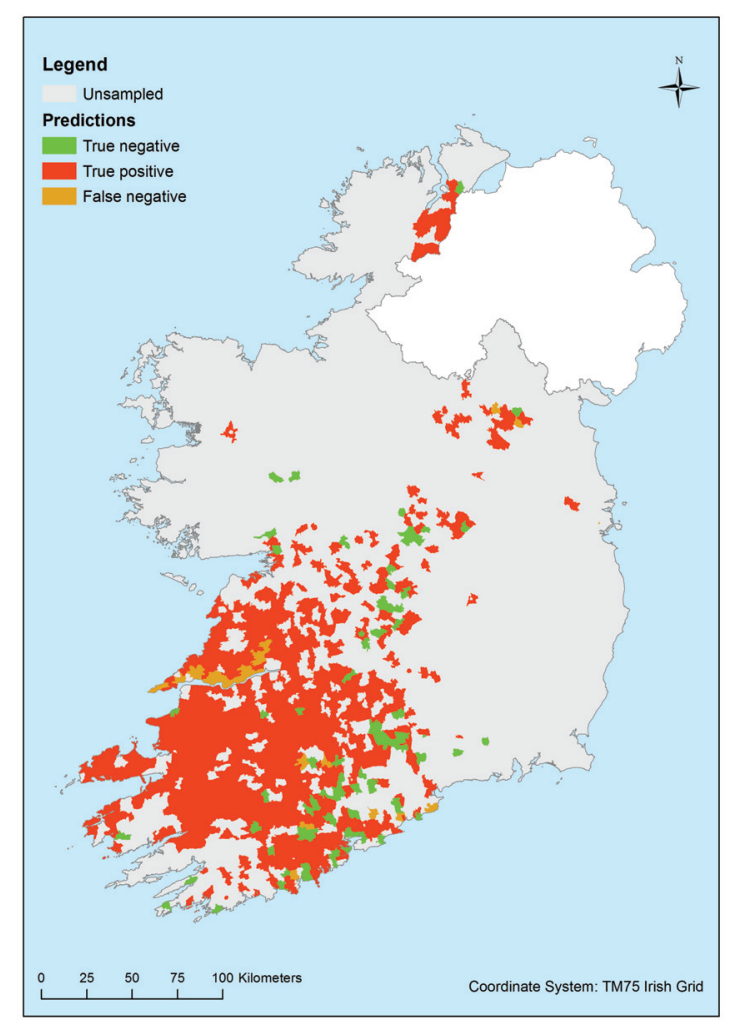

Fig. 7. Map of Ireland illustrating the true negative, true positive and false negative predicted electoral divisions with respect to F. hepatica exposure. 
cattle to graze outdoors for most of the year (Läpple et al., 2012). This farming system can allow greater exposure to F. hepatica and, therefore, the collection of BTM samples during autumn in the current study was ideal for evaluating the prevalence of fasciolosis, as this time period is near the expected peak of annual exposure to $F$. hepatica due to pasture contamination in late summer (Salimi-Bejestani et al., 2005).

To develop a spatial distribution model for fasciolosis, several climatic and environmental variables were examined for their importance as potential risk factors using RF modelling and spatial statistical analysis. The most important classes of predictors were mainly precipitation and also temperature. Therefore, in the temperate Irish climate with year-round rainfall, precipitation is essential for the completion of the F. hepatica life cycle, whereas temperature is the limiting factor. This is in agreement with the study by Malone et al. (1998), who found that greater risk for fasciolosis occurred in areas of high annual rainfall, with the risk decreasing in regions characterized by lower temperatures. These results are also consistent with the study by Yilma and Malone (1998), who showed that rainfall can increase the risk of fasciolosis, and that low temperature can retard the completion of the infection cycle. Similarly, Bossaert et al. (1999) showed that temperature was the major bioclimatic factor of the transmission of F. hepatica and Mitchell (2002) concluded that mild weather and summer rainfall are associated with high prevalence of fasciolosis. The study outcome is in concordance with the mixed forecasting model for the temporal and spatial transmission of fasciolosis in the Andes, using weather variables (mainly temperature and rainfall) and the normalized difference vegetation index (NDVI), which displays the overall response of vegetation to rainfall (Fuentes, 2004, 2006; Fuentes et al., 2005). It is also in agreement with the significant relationship that was found between temperature-adjusted rainfall and NDVI with the prevalence of fasciolosis in Australia (Durr et al., 2005). Similarly, Bennema et al. (2011) found that annual rainfall was a significant risk factor for fasciolosis and McCann et al. (2010a,b) demonstrated that rainfall and temperature were major predictors for the exposure to F. hepatica. Finally, the results of the current study are in close agreement with Martins et al. (2012), who found that high risk regions for fasciolosis were correlated with temperature and precipitation. The findings in our study are, however, in contrast to those by Kuerpick et al. (2013) who found that temperature and precipitation were not strongly correlated with the seropositivity to $F$. hepat- $i c a$, a fact probably due to the low level of spatial variation in Germany.

In the present study, the most important predictor for fasciolosis was the average of annual total number of rain-days for the period 1981-2010, followed by total amount of rainfall during September, winter and autumn of 2012 and the average of annual total number of wet-days for the period 1981-2010. The importance of annual total number of rain-days and wetdays may highlight the role of sufficient moisture during the whole life cycle of $F$. hepatica required for the development of the different stages of the parasite and the intermediate snail host. Also, it may indicate that the variables describing the daily precipitation levels might outperform those measuring the total monthly or seasonal precipitation regarding their significance as risk factors for fasciolosis.

These findings are in agreement with the study by McCann et al. (2010a), who found that rainfall and mean monthly rainy days were important parameters for the spatial modelling of fasciolosis. However, in that study, the 5-year average rainfall data were stronger predictors for fasciolosis than precipitation in the year of sampling, which is in contrast to our findings where the contemporary climatic data outperformed the long-term climatic data. For this reason, current annual data on the number of rain-days and wet-days (which were not available for the current model) may be more important predictors than the long-term climatic data. Among other important predictors were total amount of rainfall during January and March of 2012, a finding partially in agreement with that by McCann et al. (2010a), who showed that the total amount of rainfall between February and April was a significant risk factor for the F. hepatica antibody levels in November, indicating the importance of the moist pastures as suitable habitats for the intermediate snail host.

Of the environmental parameters, only the soil type proved to be associated with the risk for fasciolosis but only moderately so. Deep, well-drained soils constituted the major type in the negative regions, while deep, poorly drained as well as alluvium soils had a bigger than expected proportion among the positive regions. These findings stress the role of soil properties and drainage with respect to survival, movement and development of the snail hosts. They are also are consistent with the study by McCann et al. (2010a), who stressed that soil types can be predictors of fasciolosis. Moreover, Charlier et al. (2011) showed that drainage is likely to be negatively associated with the risk of the disease, explaining the lower than expected propor- 
tion of positive regions in deep, well-drained soils. The role of alluvium soil, which is usually found near river and stream courses, could be attributed to the importance of irrigation and wet pasture for the development of the intermediate snail host (Torgerson and Claxton, 1999). However, further studies are required to determine how this association may be explained.

This is the first study assessing the spatial exposure of Irish dairy cow herds to F. hepatica and the first attempt to develop a risk model for fasciolosis in Ireland. The high prevalence of the disease suggests that fasciolosis should be recognized as an important production problem of Irish cattle farming. The results of this study show that specific climatic and environmental risk factors support a robust distribution model that will improve the prevention and control of fasciolosis in Ireland.

\section{Acknowledgements}

The authors gratefully acknowledge the assistance and cooperation of Teagasc advisors and farmers in providing samples for this study. We also thank Met Éireann and Seamus Walsh for supplying weather data. The CORINE Land Cover (CLC2006) dataset for Ireland was sourced from EPA. Soils and Subsoils data generated by Teagasc with the co-operation of the Forest Service, EPA and GSI. Project completed May 2006. Maps of Ireland and electoral divisions were sourced from the Urban Institute of Ireland. The research leading to these results has received funding from the European Community's Seventh Framework Programme (FP7/2007-2013) under grant agreement no. 288975.

\section{References}

Benaglia T, Chauveau D, Hunter DR, Young D, 2009. Mixtools: an $\mathrm{R}$ package for analyzing finite mixture models. J Stat Softw 32, 1-29.

Bennema S, Vercruysse J, Claerebout E, Schnieder T, Strube C, Ducheyne E, Hendrickx G, Charlier J, 2009. The use of bulktank milk ELISAs to assess the spatial distribution of Fasciola hepatica, Ostertagia ostertagi and Dictyocaulus viviparus in dairy cattle in Flanders (Belgium). Vet Parasitol 165, 51-57.

Bennema SC, Ducheyne E, Vercruysse J, Hendrickx G, Claerebout E, Charlier J, 2011. Relative importance of management, meteorological and environmental factors in the spatial distribution of Fasciola hepatica in dairy cattle in a temperate climate zone. Int J Parasitol 41, 225-233.

Bloemhoff Y, Sayers R, Byrne N, Good B, 2012. Liver fluke in Irish dairy herds. Teagasc Res 7, 32-33.

Bossaert K, Lonneux JF, Losson B, Peeters J, 1999. Fasciolosis incidence forecasts in Belgium by means of climatic data. Ann
Med Vet 143, 201-211.

Breiman L, 2001. Random Forests. Mach Learn 45, 5-32.

Charlier J, Bennema SC, Caron Y, Counotte M, Ducheyne E, Hendrickx G, Vercruysse J, 2011. Towards assessing fine-scale indicators for the spatial transmission risk of Fasciola hepatica in cattle. Geospat Health 5, 239-245.

Charlier J, Meyns T, Soenen K, Vercruysse J, 2013. Monitoring gastrointestinal and liver fluke infections in Belgium by bulk tank milk ELISA: are we making progress in parasite control? Vlaams Diergen Tijds 82, 17-22.

Charlier J, Van der Voort M, Hogeveen H, Vercruysse J, 2012. ParaCalc ${ }^{\circledR}$ - A novel tool to evaluate the economic importance of worm infections on the dairy farm. Vet Parasitol 184, 204211.

Creighton P, Kennedy E, Boland T, Shalloo L, O'Donovan M, 2011. A survey analysis of grassland dairy farming in Ireland, investigating grassland management, technology adoption and sward renewal. Grass Forage Sci 66, 251-264.

Cutler R, Edwards TC, Bear KH, Cutler A, Hess KT, Gibson J, Lawler JJ, 2007. Random Forests for classification in ecology. Ecology 88, 2783-2792.

Daly K, Fealy R, 2007. Digital soil information system for Ireland. Scoping study (2005-S-DS-22-M1). Final report. Environmental Protection Agency, Wexford, Ireland.

de Waal T, Relf V, Good B, Gray J, Murphy T, Forbes A, Mulcahy G, 2007. Developing models for the prediction of Fasciolosis in Ireland. In: Making science work on the farm: a workshop on decision support systems for Irish agriculture. Holden NM, Hochstrasser T, Schulte RPO, Walsh S (eds). Dublin, AGMET, 60-63 pp.

Durr PA, Tait N, Lawson AB, 2005. Bayesian hierarchical modelling to enhance the epidemiological value of abattoir surveys for bovine fasciolosis. Prev Vet Med 71, 157-172.

Dutra LH, Molento MB, Naumann CR, Biondo AW, Fortes FS, Savio D, Malone JB, 2010. Mapping risk of bovine fasciolosis in the south of Brazil using geographic information systems. Vet Parasitol 169, 76-81.

European Environment Agency (EEA), 2007. CLC 2006 technical guidelines - Technical report 17/2007. Available at: http://www.eea.europa.eu/publications/technical_report_2007 _17 (accessed on March 2014).

Fossitt JA, 2000. A Guide to Habitats in Ireland. Heritage Council, Kilkenny.

Fuentes MV, 2004. Proposal of a geographic information system for modelling zoonotic fasciolosis transmission in the Andes. Parasitol Lationam 59, 51-55.

Fuentes MV, 2006. Remote sensing and climate data as a key for understanding fasciolosis transmission in the Andes: a review and update of an ongoing interdisciplinary project. Geospat Health 1, 59-70.

Fuentes MV, Malone JB, 1999. Development of a forecast system for fasciolosis in central Chile using remote sensing and 
climatic data in a geographic information system. Res Rev Parasitol 59, 129-134.

Fuentes MV, Sainz-Elipe S, Nieto P, Malone JB, Mas-Coma S, 2005. Geographical information systems risk assessment models for zoonotic fasciolosis in the South American Andes region. Parassitologia 47, 151-156.

Höglund J, Dahlström F, Engström A, Hessle A, Jakubek E, Schnieder T, Strube C, Sollenberg S, 2010. Antibodies to major pasture borne helminth infections in bulk-tank milk samples from organic and nearby conventional dairy herds in southcentral Sweden. Vet Parasitol 171, 293-299.

Kaplan RM, 2001. Fasciola hepatica: a review of the economic impact in cattle and considerations for control. Vet Ther 2, 4050 .

Kuerpick B, Conraths FJ, Staubach C, Fröhlich A, Schnieder T, Strube C, 2013. Seroprevalence and GIS-supported risk factor analysis of Fasciola hepatica infections in dairy herds in Germany. Parasitology 140, 1051-1060.

Kuerpick B, Schnieder T, Strube C, 2012. Seasonal pattern of Fasciola hepatica antibodies in dairy herds in Northern Germany. Parasitol Res 111, 1085-1092.

Läpple D, Hennessy T, O’Donovan M, 2012. Extended grazing: a detailed analysis of Irish dairy farms. J Dairy Sci 95, 188195.

Malone JB, Gommes R, Hansen J, Yilma JM, Slingenberg J, Snijders F, Nachtergaele F, Ataman E. 1998. A geographic information system on the potential distribution and abundance of Fasciola hepatica and F. gigantica in east Africa based on Food and Agriculture Organization databases. Vet Parasitol 78, 87-101.

Malone JB, Zukowski SH, 1992. Geographic models and control of cattle liver flukes in the Southern USA. Parasitol Today 8, 266-270.

Martins IVF, de Avelar BR, Pereira MJ, da Fonseca AH, 2012. Application of a geographical information system approach for risk analysis of fascioliasis in southern Espirito Santo state, Brazil. Geospat Health 6, 87-93.

Mas-Coma S, Valero MA, Bargues MD, 2009. Climate change effects on trematodiases, with emphasis on zoonotic fascioliasis and schistosomiasis. Vet Parasitol 163, 264-280.

McCann CM, Baylis M, Williams DJL, 2010a. The development of linear regression models using environmental variables to explain the spatial distribution of Fasciola hepatica infection in dairy herds in England and Wales. Int J Parasitol 40, 1021 1028.

McCann CM, Baylis M, Williams DJL, 2010b. The seroprevalence and spatial distribution of Fasciola hepatica infected dairy herds in England and Wales. Vet Rec 166, 612-617.

Mitchell G, 2002. Update on fasciolosis in cattle and sheep. In Practice 24, 378-385.

Murphy TM, Fahy KN, McAuliffe A, Forbes AB, Clegg TA, O'Brien DJ, 2006. A study of helminth parasites in culled cows from Ireland. Prev Vet Med 76, 1-10.

Rapsch C, Dahinden T, Heinzmann D, Torgerson PR, Braun U, Deplazes P, Hurni L, Bär H, Knubben-Schweizer G, 2008. An interactive map to assess the potential spread of Lymnaea truncatula and the free-living stages of Fasciola hepatica in Switzerland. Vet Parasitol 154, 242-249.

R Core Team, 2013. R: a language and environment for statistical computing. R Foundation for Statistical Computing, Vienna, Austria. Available at: http://www.R-project.org/ (accessed on June 2014).

Rodriguez-Galiano V, Mendes MP, Garcia-Soldado MJ, ChicaOlmo M, Ribeiro L, 2014. Predictive modeling of groundwater nitrate pollution using Random Forest and multisource variables related to intrinsic and specific vulnerability: a case study in an agricultural setting (Southern Spain). Sci Total Environ 476, 189-206.

Salimi-Bejestani MR, Daniel RG, Felstead SM, Cripps PJ, Mahmoody H, WilliamS DJ, 2005. Prevalence of Fasciola hepatica in dairy herds in England and Wales with an ELISA applied to bulk-tank milk. Vet Rec 156, 729-731.

Schweizer G, Braun U, Deplazes P, Torgerson PR, 2005. Estimating the financial losses due to bovine fasciolosis in Switzerland. Vet Rec 157, 188-193.

Selemetas N, Phelan P, O’ Kiely P, de Waal T, 2014. Weather and soil type affect incidence of Fasciolosis in dairy cow herds. Vet Rec 175, 371.

Smith G, 2011. Models of macroparasitic infections in domestic ruminants: a conceptual review and critique. Rev Sci Tech 30, 447-456.

Torgerson P, Claxton JR, 1999. Epidemiology and control. In: Fasciolosis. Dalton JP (ed). Oxon and New York, CABI Publishing, 113-149 pp.

Tum S, Puotinen ML, Coppeman DB, 2004. A geographic information systems model for mapping risk of fasciolosis in cattle and buffaloes in Cambodia. Vet Parasitol 122, 141-149.

Tum S, Puotinen ML, Skerratt LF, Chan B, Sothoeun S, 2007. Validation of a geographic information system model for mapping the risk of fasciolosis in cattle and buffaloes in Cambodia. Vet Parasitol 143, 364-367.

Valencia-López N, Malone JB, Carmona CG, Velásquez LE, 2012. Climate-based risk models for Fasciola hepatica in Colombia. Geospat Health 6, 67-85.

Walsh S, 2012. A summary of climate averages 1981-2010 for Ireland. Climatological note no.14. Dublin, Met Éireann.

Yilma JM, Malone JB, 1998. A geographic information system forecast model for strategic control of fasciolosis in Ethiopia. Vet Parasitol 78, 103-127.

Zukowski SH, Wilkerson GW, Malone JB, 1993. Fasciolosis in cattle in Louisiana. II. Development of a system to use soil maps in a geographical information system to estimate disease risk on Louisiana coastal marsh rangeland. Vet Parasitol 47, 51-65. 